IZA DP No. 8077

Does Labor Legislation Benefit Workers?

Well-Being after an Hours Reduction

Daniel S. Hamermesh

Daiji Kawaguchi

Jungmin Lee

March 2014 


\title{
Does Labor Legislation Benefit Workers? Well-Being after an Hours Reduction
}

\author{
Daniel S. Hamermesh \\ Royal Holloway University of London,
Daiji Kawaguchi
Hitotsubashi University
and IZA \\ Jungmin Lee \\ Sogang University \\ and IZA
} University of Texas at Austin, IZA and NBER

Discussion Paper No. 8077

March 2014

\author{
IZA \\ P.O. Box 7240 \\ 53072 Bonn \\ Germany \\ Phone: +49-228-3894-0 \\ Fax: +49-228-3894-180 \\ E-mail: iza@iza.org
}

\begin{abstract}
Any opinions expressed here are those of the author(s) and not those of IZA. Research published in this series may include views on policy, but the institute itself takes no institutional policy positions. The IZA research network is committed to the IZA Guiding Principles of Research Integrity.

The Institute for the Study of Labor (IZA) in Bonn is a local and virtual international research center and a place of communication between science, politics and business. IZA is an independent nonprofit organization supported by Deutsche Post Foundation. The center is associated with the University of Bonn and offers a stimulating research environment through its international network, workshops and conferences, data service, project support, research visits and doctoral program. IZA engages in (i) original and internationally competitive research in all fields of labor economics, (ii) development of policy concepts, and (iii) dissemination of research results and concepts to the interested public.
\end{abstract}

IZA Discussion Papers often represent preliminary work and are circulated to encourage discussion. Citation of such a paper should account for its provisional character. A revised version may be available directly from the author. 


\title{
ABSTRACT
}

\section{Does Labor Legislation Benefit Workers? Well-Being after an Hours Reduction*}

\begin{abstract}
Are workers in modern economies working "too hard" - would they be better off if an equilibrium with fewer work hours were achieved? We examine changes in life satisfaction of Japanese and Koreans over a period when hours of work were cut exogenously because employers suddenly faced an overtime penalty that had become effective with fewer weekly hours per worker. Using repeated cross sections we show that life satisfaction in both countries may have increased relatively among those workers most likely to have been affected by the legislation. The same finding is produced using Korean longitudinal data. In a household model estimated over the Korean cross-section data we find some weak evidence that a reduction in the husband's work hours increased his wife's well-being. Overall these results are consistent with the claim that legislated reductions in work hours can increase workers' happiness.
\end{abstract}

JEL Classification: J22, J23, J28

Keywords: happiness, overtime work, rat-race

Corresponding author:

Daniel S. Hamermesh

Royal Holloway University of London

Department of Economics

214 Horton Building

Egham, Surrey TW20 0EX

United Kingdom

E-mail: Daniel.Hamermesh@rhul.ac.uk

\footnotetext{
* We thank Andrew Clark, Andrew Oswald, Eva Poen, participants at seminars at several universities, and especially Steve Trejo for helpful comments.
} 


\section{Background}

Labor legislation existed in ancient economies, is ubiquitous today, and is usually justified as benefiting a particular group of workers. Much of the discussion surrounding these laws is about their overall effect on labor markets. What has hardly ever been examined is whether those workers at whom the legislation is targeted do in fact view themselves as having benefited from it. In this study we consider this question in light of a model of the impact of two particular pieces of legislation that increased employers' disincentives to employ overtime hours.

In some cases the discussions surrounding a piece of labor legislation suggest that its purpose is to benefit society by restricting the behavior of some agents who may be directly affected (e.g., “workspreading” under the overtime and child-labor provisions of the U.S. Fair Labor Standards Act of 1938). In other cases the legislation is rationalized as benefiting a group of workers who are believed to have been subjected to some adverse working condition (e.g., the U.S. Occupational Safety and Health Act of 1970, and the U.S. Keating-Owen Act of 1916 limiting child labor). The question in these latter instances is whether the "protected" group is better off because of the protection.

Until the mid-1980s the work year in Japan was one of the longest among wealthier nations. Indeed, karoshi-death from overwork - was viewed as causing the demise of as many as 10,000 Japanese workers per year (Nishiyama and Johnson, 1997). Partly in response to concerns about excessive work, between the mid-1980s and mid-1990s Japan reduced the standard workweek from 48 to 40 hours, hoping to reduce employers' incentives to demand long workweeks. In Korea, also partly due to worries about death from overwork (kwarosa), the standard workweek was reduced from 44 to 40 hours between 1999 and 2009. ${ }^{1}$

The question here is whether those workers at whom reductions in work hours were targeted actually did benefit from the legislation aimed at aiding them. There is no question that these legislative changes directly affected hours: In Lee et al (2012) we showed that the Japanese overtime legislation and

\footnotetext{
${ }^{1}$ See http://english.yonhapnews.co.kr/n_feature/2013/04/24/61/4901000000AEN20130424009700315F.HTML .
} 
the similar Korean legislation over a decade later did reduce work hours economy-wide. And Kawaguchi et al (2013) demonstrated that in both countries the reduction was especially great among workers in those demographic groups that were targeted-workers in groups that had especially long work hours before the legislation's enactment.

An obvious cost of an exogenous reduction of work hours is the reduction of output. Indeed, Hayashi and Prescott (2002) claim that the reduction of work hours was part of the reason why Japan experienced a decade-long stagnation in the $1990 \mathrm{~s}^{2}$ The workings of competition in a labor market will equate the marginal rate of substitution of consumption for leisure to the marginal product of labor. This equality leaves no room for labor regulations to improve the welfare of workers. Indeed, the demand-side incentives that successfully lead employers to cut work time will reduce the well-being of the affected workers. $^{3}$

It is possible, however, that information asymmetries and externalities are prevalent in the labor market—in particular, that the need to cooperate in the workplace creates a "rat-race” (Akerlof, 1976) that generates sub-optimal excess effort. For examples, a law firm's inability to learn its associates' commitment to the firm may cause a rat race among its associates (Landers et al, 1996); a workaholic boss may impose inefficiently long work hours on his co-workers who are better off staying with him than going elsewhere (Hamermesh and Slemrod, 2008). As another possibility, high unemployment and/or monopsony (Manning, 2003) might give employers the power to exploit workers, leading hours to depart from what they would be in the utility-maximizing hours-wage package.

Given the relevance of these possible market failures to the labor market, we ask if the regulation of work hours at least improves indices of the welfare of targeted workers, namely their life satisfaction.

\footnotetext{
${ }^{2}$ They do not, however, mention any effect on welfare or well-being, because they adopted a reduced-form model in which the reduction of work hours in equilibrium is induced by a change in preferences.

${ }^{3}$ A layperson's view of this worsening was cogently expressed by Matias (2002, p. 7): “While the Eight-Hour-Day Restoration and Workplace Flexibility Act was intended to 'protect California's working people' as it has for over 80 years, in fact it eliminates a great deal of workplace flexibility by prohibiting the employer and employee from tailoring their working relationship to suit each other's needs. The law no longer permits employees to take comp time in lieu of pay for extra hours worked.”
} 
It thus also speaks to the general question of whether, at least along the dimension of hours of work, a modern labor market produces outcomes that may be sub-optimal for some workers even at times of full employment.

Pezzini (2009) is perhaps the closest relative of this study, although she focused on fairly general changes and thus could not link legislative changes to those particular individuals most likely to be affected by them. Ludwig et al (2012) did do this, demonstrating that the happiness and physical and mental health of individuals who were randomly selected into an experiment in housing mobility rose relative to those not selected. Neither of these studies focuses on particular legislation. Estevao and Sá (2008) did examine the effects of the imposition of a 35-hour workweek in France, but they focused only on the narrow and very partial question of satisfaction with work hours and could not identify those workers most likely to have been affected by the law. No study has examined whether the purported direct beneficiaries of any labor legislation actually feel themselves generally better off as a result of the legislation and can thus be viewed as having benefited from its enactment. ${ }^{4}$

\section{Institutional, Empirical and Theoretical Motivation}

As Kawaguchi et al (2013) discuss, in Japan in the 1980s and in Korea in the early 2000s, legislation was enacted to provide incentives to `reduce long hours. In Japan the law began to be implemented in 1988, cutting standard hours from 48 to 40 and extending the 25 percent overtime penalty to those hours, although there were exemptions for small- and medium-sized establishments and establishments belonging to industries with long hours. By 1994, except for a few industries with long hours, and for some smaller establishments, the law was fully effective. Even these exemptions ended early in 1997. In Korea a law lowering standard hours from 44 to 40 was passed in 2000 and began to be applied in mid-2004, initially covering workplaces of 1000+ employees, and by mid-2008 applying to all but the smallest establishments (with overtime hours penalized at 50 percent).

\footnotetext{
${ }^{4}$ One effort (Gruber and Mullainathan, 2005) analyzed how increased taxes on cigarettes affected smokers' happiness.
} 
Consider the impact of a change in legislated overtime provisions (in standard hours). We use the example of Japan, with standard hours dropping from 48 to 40, but we could easily present the example, mutatis mutandis, of Korea's cut in standard hours from 44 to 40. Figure 1a depicts this change in the standard textbook case, with workers "optimally” choosing their hours after standard hours drop from 48 to 40. In this case workers who maintain their jobs are unequivocally at least as well off as before the legislation, even if the employer chooses their hours of work for them along this new constraint. ${ }^{5}$

There is substantial evidence (Trejo, 1991) that hourly wage rates drop when the overtime penalty is increased. Redrawing the description to reflect this fact yields Figure 1b, which we have drawn for the special case where total earnings are fixed. The graph shows that if the regular hourly wage rate is decreased sufficiently, the legislation can make workers worse off. If we had drawn the Figure with an even larger decline in the hourly wage, or a larger cut in hours in response to the cut in standard hours, an improvement in well-being would have been still less likely.

While the model in Figure 1a shows that the legislation might improve workers' welfare, noncompetitive models can also yield situations in which a cut in standard hours raises employees' wellbeing. Reducing exploitation by imposing a limit on hours worked can raise workers' welfare in a monopsony model. So too, in a rat-race model in which workers put in sub-optimal excess effort to distinguish themselves from slightly inferior workers (Akerlof, 1976), imposing a limit on hours will increase at least some workers' utility. ${ }^{6}$ Less closely related models, such as Layard's (2006) view of the effects of jealousy on labor supply, or the Levine et al (2013) model of peer pressure, could also generate what appears to be a rat-race equilibrium in hours of work.

This discussion should demonstrate that the net effect of hours legislation on the well-being of those workers who are targeted depends on a variety of factors and is at the end of the day an empirical

\footnotetext{
${ }^{5}$ Going back to Ehrenberg (1971) and continuing in Hart (2004), the evidence is pretty clear that such legislation would induce an increase in employment, although (see Hamermesh, 1993, Chapter 4), it would probably reduce total work-hours by raising average labor costs.

${ }^{6}$ We recognize the difficulties of linking changes in objective outcomes to changes in subjective well-being (see, e.g., Stevenson and Wolfers, 2009). The difference here is that the objective outcome is a well-identified and singular legislative change, arguably not part of any inchoate social trend.
} 
issue. The essential points to note are: 1) Nothing requires the consumer's equilibrium either before or after the cut in standard hours to be one that she would have chosen freely. Indeed, even with free choice the worker could be made better off if the original equilibrium resulted from speed-ups arising from informational problems; 2) The effect on workers’ welfare cannot be inferred by looking at the change in hours - or at the change in their feelings about their hours alone. The entire earnings-hours package (and no doubt other, non-pecuniary aspects of the job too) will be affected by the legislation, suggesting at the very least that one should examine overall job satisfaction; 3) Even that approach is too narrow: There is no reason to assume that responses to imposed changes in work time are separable from decisions about allocating non-market time (suggested by the results of Kawaguchi et al, 2013, Burda and Hamermesh, 2010, and Aguiar et al, 2013). If nothing else, a change in earnings, even with no change in market hours, will affect the allocation of non-market time due to the differential complementarity of purchased goods and various uses of time. That being the case, examining how the legislated change in standard hours affects overall life satisfaction makes sense and is the best method of evaluating the welfare impact of the legislation, since any cut in work hours engendered by the cut in the standard workweek will produce effects on all outcomes arising from changes in the agent's constrained utility maximization.

\section{Data and Descriptive Statistics}

The ideal data set for analyzing the impacts of these targeted reductions in the standard workweek would be longitudinal; would contain very large random samples of workers and non-workers; would be drawn from time periods just before it became evident that the legislation would be enacted and just after its full effects would be expected to be felt; would include all the relevant demographic information necessary to impute the propensity to be affected by the legislation; and would include measures of the respondents' feelings about various characteristics of their jobs, and the job overall, as well as information on their general life satisfaction. Unsurprisingly, no data sets in either Japan or Korea satisfy all these criteria. ${ }^{7}$

\footnotetext{
${ }^{7}$ Our approach to circumventing the lack of an ideal data set (and the one we used in Kawaguchi et al, 2013) is similar to that proposed by Botosaru and Gutierrez (2014).
} 
Given the absence of a perfect set of data sets, the best available data for Japan are the National Surveys of Lifestyle Preferences (Kokumin Seikatsu Senkoudo Chosa), a series of cross-section household surveys querying one adult per household. We use the waves of 1984 and 1987, which were fielded before the overtime legislation was seriously discussed, and the surveys obtained in 1996 and 1999, which were fielded about when or after it was fully effective. Because the sample sizes in each survey are fairly small, we combine the 1984 and 1987 data sets to constitute the Pre-legislation period and combine the 1996 and 1999 data sets to constitute the Post-legislation period. In the National Surveys respondents answered, “Are you satisfied with your life, or not satisfied?” along the scale 5: satisfied - 1: dissatisfied, which we view as a measure of life satisfaction.

For Korea we use data from the General Social Surveys (Sahwe Chosa), 2003 and 2009, the former to represent the Pre-legislation period and latter to represent the Post-legislation period. One advantage of the Korean GSS is its large sample size, with the number of respondents varying from about 40,000 to 80,000 . The surveys, targeted at all adults in each surveyed household, contain a question regarding life satisfaction that is asked and coded identically to that in the Japanese surveys. Like the Japanese data sets, these have all the demographic information required to compute the scores $\pi$ indicating sample respondents' propensities to have had their hours altered by employers' responses to the legislated changes.

That we can infer that the potential impacts of these legislative actions achieved their goals of shortening workweeks of those working long hours can be seen from regressions estimating the probability of working 41-48 hours (in Japan) or 41-44 hours (in Korea). Using the example of Japan:

$$
\pi\left\{48 \geq \mathrm{H}_{\mathrm{iPOST}}>40\right\}=\gamma * \mathrm{X}_{\mathrm{iPOST}},
$$

where $\mathrm{i}$ is an individual, $\gamma^{*}$ a vector of parameter estimates from the samples Pre-legislation, $\mathrm{X}$ a vector of demographic variables, and POST denotes a time period after the legislation was enacted. ${ }^{8}$ The $\mathrm{X}$

\footnotetext{
${ }^{8}$ In the regressions we calculate $\pi$ based on the propensity to work at least 43 and no more than 48 hours because the information on usual hours in this survey is presented in brackets.
} 
variables differ between the countries, but we use all of those that were collected both the pre- and postlegislation surveys.

To minimize the reflection problem (Manski, 1993), we calculate the propensity scores in (1) by estimating logit models describing the propensity to work in time-use surveys that were conducted in each country around the Pre-period rather than from the surveys that we use to infer impacts on life satisfaction. Thus for Japan we estimate the coefficients $\gamma^{*}$ in (1) using the Japanese Time Use Survey (Shakai Seikatsu Kihon Chosa) for 1986, while for Korea we use the Korean Time Use Survey (Senghwal Sigan Chosa) for 1999. In both cases we related actual weekly hours worked (not daily diary information) to the demographics of the sample respondents.

The results of estimating these logits, shown in Table 1, demonstrate that the legislation could have had differential effects on work hours that were correlated with workers' demographic characteristics. Male, middle-aged and more educated workers were more likely to have been affected by the legislation in both countries; and we showed that it is these groups in particular for which workweeks showed the greatest declines between 1986 and 1996 in Japan, and between 1999 and 2009 in Korea. ${ }^{9}$ Using the estimates of (1), we take samples from the Japanese National Surveys and the Korean GSS before and after the legislation was effective to impute $\pi_{\text {ict }}$, the propensity that a person $\mathrm{i}$ in year $\mathrm{t}$ with demographic characteristics indicated by some combination denoted by cell c was likely to have been affected by the legislation (to have had hours in the affected range after the legislation had it not been enacted).

Table 2 presents descriptive statistics for the Japanese and Korean samples based on the Japanese National Surveys and the Korean GSS. These statistics and all the subsequent parameter estimates are based on data weighted by the sampling weights in the particular surveys. We restrict all the analyses for

\footnotetext{
${ }^{9}$ See Kawaguchi et al (2013) and Lee et al (2012). Averaging over all adults in both Japan and Korea, the amount of market work decreased by 18 minutes per average day from the Pre to the Post period. Moreover, the impact of $\pi$ on the change in work time on the average day was negative and statistically significant. A two standard-deviation change in $\pi$ in these data implied a 0.49 hour weekly decline in market work in Japan and a 3.66 hour weekly decline in Korea.
} 
Japan to people ages $15-64$, those for Korea to non-students ages $16-64 .^{10}$ In both countries the potentially affected respondents in these age ranges are more likely on average to be older, to have higher educational attainment, and to be married. On average male respondents unsurprisingly have higher propensities to have been affected by the changes in the demand for overtime work that were induced by the legislated cuts in the standard workweek. Most important, for both men and women the ranges of these propensities are very large, as are their standard deviations. This dispersion seems sufficiently large to allow us to test whether the impacts of the legislation in each country can be inferred for those people most likely to have been affected.

As is usual in the life satisfaction literature, more Japanese state that they are at least somewhat satisfied than otherwise. For both sexes in Japan the dispersion in the responses is quite large. Examining the entire distribution of responses among Japanese men, 7.2 percent of the respondents state that they are satisfied (5); 39.3 percent that they are rather satisfied (4); 29.4 percent neither satisfied nor dissatisfied (3); 17.1 percent rather satisfied (2); and 7.0 percent dissatisfied (1).

Remarkably, in the Korean data the average person rates him/herself at slightly less than the middle of the five-point distribution. Again, for both sexes the dispersion is large, although for both sexes it is less than in the Japanese data. Among men, for example, 4.3 percent of the respondents state that they are satisfied (5); 18.2 percent that they are rather satisfied (4); 50.0 percent neither satisfied nor dissatisfied (3); 21.7 percent rather dissatisfied (2); and 5.8 percent dissatisfied (1).

There are no consistent gender differences in the average extent of life satisfaction in these data. In Japan women in this age range seem to be more satisfied than men, in Korea the opposite is true. This inconsistency mirrors findings across data sets on satisfaction in four developed Western countries (Hamermesh and Abrevaya, 2013).

\footnotetext{
${ }^{10}$ The Japanese age measures are recorded in intervals, so that we cannot delete 15 -year-olds to make the samples entirely comparable to the Korean samples.
} 


\section{Basic Estimates Using Social Surveys}

The general models to be estimated here are:

$$
\mathrm{S}_{\text {ict }}=\beta_{1} \pi_{\text {ic }}+\beta_{2} \text { POST }_{\text {ict }}+\beta_{3} \pi_{\text {ic }} \text { POST }_{\text {ict }}+\varepsilon_{\text {ict }},
$$

and

$$
\mathrm{S}_{\text {ict }}=\beta_{1} \pi_{\mathrm{ic}}+\beta_{2} \mathrm{POST}_{\text {ict }}+\beta_{3} \pi_{\mathrm{ic}} \mathrm{POST}_{\text {ict }}+\beta_{4} \mathrm{X}_{\mathrm{ict}}+\beta_{5} \mathrm{X}_{\mathrm{ict}} \mathrm{POST}_{\text {ict }}+\varepsilon_{\text {ict }},
$$

where $\mathrm{S}$ is life satisfaction, $\pi$ is the propensity that a person in group c will be affected by the legislation, POST is time after the legislation has become effective, $\mathrm{X}$ is a vector of the individual's characteristics, $\mathrm{i}$ is an individual, $\mathrm{t}$ is time (Pre- or Post-legislation), $\varepsilon$ is an error term, and the $\beta$ are the parameters that we will estimate. Equation (2a) is a standard double-difference approach, with the methodological twist that the treatment-control difference is not bivariate but rather varies along the unit interval of the propensity score (scaled throughout as a percentage). Equation (2b) accounts for the effects of demographic differences and allows their impacts to differ in the Pre- and Post-periods. ${ }^{11}$ We estimate (2) separately for men and women, since the literature demonstrates that the determinants of measures of satisfaction/happiness differ by gender (e.g., Frijters et al, 2004; Blanchflower and Oswald, 2004; Clark et al, 2008). While we only present least-squares estimates of (2), in every case we also estimated the appropriate ordered probits, obtaining results that were qualitatively identical to those presented in the tables.

\section{A. Life Satisfaction in Japan}

Before discussing the estimates of (2) for Japan we examine the simple means of changes in life satisfaction by quartiles of the distributions of the imputed $\pi$. These are shown in Figures $2 \mathrm{a}$ and $2 \mathrm{~b}$ separately for men and women. While the increase in satisfaction with $\pi$ is not always monotonic, in general we observe the largest increases (actually, the smallest decreases) among those people with the highest likelihood of having been affected by the legislation.

\footnotetext{
${ }^{11}$ Specification (2b) makes identification of the treatment dependent on the nonlinearity of the logit formulation. We deal with this difficulty at substantial length in the Sub-section C.
} 
In Table 3 we present the parameter estimates of (2a) and (2b), describing the responses on the five-point life-satisfaction measure. Although they are not presented in the Table, the estimated effects of the variables in $\mathrm{X}$ in (2b) are standard in the literature: U-shaped effects of age, with troughs in the forties, positive effects of educational attainment and a positive effect of being married.

The estimates of $\beta_{3}$ in (2a) are both positive, and the impact on female life satisfaction is highly significant statistically. Taking these estimates and the standard deviations of $\pi$ and life satisfaction, the effect of a two standard-deviation increase in $\pi$ on life satisfaction among men (women) is 0.07 (0.16) standard deviations. Extrapolating far above the highest cell propensity—going from a man (woman) whose hours without the legislation would surely have been below 43 or more than 48 to someone whose hours would certainly have been within that range—would increase life satisfaction by 0.63 (1.74) standard deviations.

Estimating (2b) on these Japanese data yields results for both men and women with the estimated $\beta_{3}$ both significant and absurdly large. Their sizes point up a fundamental identification problem with these estimates which we will address later in this Section. There clearly was an increase in life satisfaction that is positively correlated with the demographic characteristics that predict that an individual was more likely to have been affected by the legislation. Was the cause of this increase the legislation, or was there some other force that just happened to raise satisfaction especially rapidly (actually, prevent it from falling as rapidly) among those same individuals relative to others?

Regardless of the answer to this crucial question, in no way do we claim that the satisfaction indicator measures cardinal utility. Our results for Japan do, however, indicate that those who are most likely to have had their hours constrained by the legislation did see their well-being, measured as well as possible, increased on average by not insubstantial amounts relative to that of other people.

\section{B. Life Satisfaction in Korea}

Figures $3 \mathrm{a}$ and $3 \mathrm{~b}$ show the means of the changes in average life satisfaction by quartile of the distributions of $\pi$ separately for Korean men and women. For women the increase is monotonic across 
the quartiles, while for men the main difference is between the upper three quartiles and the lowest quartile of the distribution.

Table 4 presents the results for Korea analogous to those in Table 3. As with the Japanese results, the (untabled) estimates of the impacts of the variables in the vector $\mathrm{X}$ are standard: Life satisfaction is higher among the more educated and among married individuals and is inverse U-shaped in age, as in the Japanese data. As in those date, average life satisfaction is lower in the later period.

The estimates of (2a) are qualitatively identical to those for Japan. For men but not for women in Korea we observe significantly differentially higher life satisfaction in 2009 than in 2003 among people whose characteristics would in 1999 have made them more likely to have been working between 40 and 44 hours in 2009 absent the legislation. A two standard-deviation increase in the propensity to have been affected by the legislation increased male (female) life satisfaction by 0.05 (0.02) standard errors. Going far beyond the sample range, moving from a person whose hours would certainly not have been in the affected range to one whose hours certainly would have been, the legislated impact on life satisfaction would have been 0.25 (0.24) standard deviations among men (women). These effects of the legislation are also in line quantitatively with those we showed for Japan, albeit somewhat smaller.

While the estimates of ( $2 b)$ in Korea do not generate absurdly large positive estimates of $\beta_{3}$, the estimate for men becomes negative and statistically insignificant, while that for women remains positive and insignificant. The reversal for men suggests that, as with the Japanese results, we are unable to distinguish between the possibility that those most likely to have been affected by the legislation had their relative satisfaction increased because of the legislation from the alternative possibility—-that people with these demographics saw an increase in their relative satisfaction during this period independent of it. ${ }^{12}$

\footnotetext{
${ }^{12}$ If we only include the controls $X$ without interactions with D2009, the estimates of $\beta_{3}$ are very similar to those in the specification (2a) here and in Table 4. In comparison to the estimates of (2b) this finding suggests that, in any study that essentially uses successive cross-sections to estimate double-differences with controls, it is crucial to include interactions of the latter with an indicator for the equivalent of the "Post" period. A substantial number of studies have used cross-sections of data to estimate double-differences or their equivalent including covariates, but without their interactions with a "Post" or "Pre" indicator (e.g., Abramitzky et al, 2011, on marriage; Dynarski, 2002, on education).
} 


\section{Correlated Trends or Legislated Effects on Life Satisfaction?}

To circumvent difficulties in distinguishing the effects of the legislation from those of trends in relative satisfaction that were specific to the groups likely to have been affected by the legislation, we create what are essentially placebo tests for changes in relative satisfaction after the legislation (in Japan) and before the legislation (in Korea). ${ }^{13}$ We examine whether the correlated relative changes that we observed in the estimates in the previous sub-sections were parts of trends that began before (Korea) or continued after (Japan) the period when the legislation was becoming effective.

For Japan the 2002 and 2005 waves of the National Surveys asked the same questions that we used in the estimates in Table 3. Combining these in order to obtain larger samples, and imputing the same propensity scores $\pi_{\text {ic }}$ to the sample respondents in those years, we re-estimate (2a) and (2b) comparing responses in 1996 and 1999 to those in 2002 and 2005. Thus we are essentially asking whether the correlated trends that might have been generating the results in Sub-section A persisted in the half-decade after the legislation became fully effective.

The first two columns of Table 5 present the results of estimating (2a) over this "Post-Post" period. They should be compared to those in Columns (1) and (3) of Table 3. As in Table 3 the estimates of (2a) for men suggest that there also was no correlated trend in relative life satisfaction during this PostPost period. Among women, however, the results are different here: While relative life satisfaction increased among those Japanese women most likely to have been affected during the time the legislation was implemented, there was no similar relative trend after this time. ${ }^{14}$

Given the timing of the legislation, we cannot perform the same comparisons for the period after the legislation was fully effective in Korea as we did for Japan. Moreover, because the Korean GSS do not contain responses on life satisfaction for the period before the legislation was implemented, we cannot make a "Pre-Pre" to Pre comparison of changes in relative life satisfaction across demographic groups

\footnotetext{
${ }^{13}$ Regrettably there are no comparable data before the Pre period in Japan.

${ }^{14}$ Comparisons of the estimates of (2b) in Table 3 to those of (2b) for the Post and Post-Post period yield similar inferences for men.
} 
using the GSS. The World Values Survey for Korea for 1990 and 2001 did, however, contain the same demographics as in the GSS, and it also included responses about life satisfaction, which were coded on a 10 to 1 scale. We identify 1990 as the Pre-Pre period and 2001 as the Pre period, and we re-estimate (2a) using this comparison. We impute propensity scores for both years in the WVS using the same equations that were used to impute the scores in the GSS that underlay the results in Table 4.

The results of this re-estimation are presented in the third and fourth columns of Table 5 and are comparable to the estimates in Columns (1) and (3) of Table 4. As with the Japanese results, among women here there is no trend (before the legislation in this case) in relative life satisfaction that is correlated with the propensity to have been affected by the legislation. Among Korean men, however, there is a correlated significant negative trend before the legislation began to be implemented: Those men who were more likely to have been affected by the law saw their relative satisfaction decline before the implementation. This result is the reverse of what we observed for Korean men in the estimates of (2a) in Table 4 for men. This placebo test strengthens the conclusion that the results there for Korean men arise from the impacts of the law. ${ }^{15}$

Perhaps other factors were varying during the experimental period in such a way as to raise the life satisfaction of those workers who were most likely to have been affected by the law. One possibility is that tax rates became less progressive (and thus relatively lower for the highly-educated, middle-aged workers who were most likely to have worked long hours). While in Japan the tax structure did become slightly less progressive over the "treatment" period, there was no change in progressivity in Korea during its "treatment" period. Another possibility is that the returns to schooling and experience, both variables that raise the imputed $\pi$, rose during this period. In Japan, as the estimates in Kambayashi et al (2008) show, exactly the opposite happened; and in Korea an examination of wage ratios between various

\footnotetext{
${ }^{15}$ The re-estimates of (2b) for the Pre-Pre and Pre periods yield results for women that are similar to those shown for Korea in Table 5. Among men the significant negative trend in that Table disappears in those re-estimates: The estimated $\beta_{3}$ is tiny and statistically insignificant. Clearly, regardless of the specification there was no correlated positive trend in life satisfaction before the law was implemented.
} 
quantiles shows no increase between the $90^{\text {th }}$ and the median or $10^{\text {th }}$ percentiles of earnings during the treatment period.

One group that includes some middle-aged and highly-educated workers is the self-employed. Their life satisfaction should not have been affected by the legislation. To examine this we re-estimate (2a) on sub-samples restricted to individuals in Korea who were self-employed. (The Japanese data sets for 1984 and 1987, the pre-legislation years, lack information on self-employment status.) The estimates of $\beta_{3}$ are negative for men and women, with t-statistics far below one.

We cannot exclude the possibility that the significant positive effects that we found in Subsections A and B among women in Japan and among men in Korea were not the results of temporary changes that occurred during the time the legislation was becoming effective in each country. We can, however, conclude that these impacts, and the insignificant but positive impacts among Japanese men and Korean women, were not parts of continuing trends in relative satisfaction that were occurring in each country. At the very least we have found no evidence that those workers most likely to have been affected by the legislation were worse off as a result.

\section{Estimates Using the Korean Labor and Income Panel Study (KLIPS)}

The KLIPS is Korea's longitudinal household survey. Its start preceded the legislation we are examining, and here we use the 1999 and the 2009 waves, the former because it is the last that clearly precedes serious discussion of the legislation, the latter because the implementation of the legislation had by then been completed (and it is the same year that we used as the Post period in the previous section). These data provide the chance to compare changes in the behavior of specific people who would or would not have qualified for coverage in the base year, clearly justifying using this information. They do not obviate the difficulties of distinguishing changes in relative satisfaction due to other causes from those due to the legislation; but they do remove any problems that result from the need to impute propensity scores to the sample respondents. The trade-off for this gain is that the requirement that the respondent worked for pay in both the Pre- and Post- periods means that the sample is selected on those people with the closest attachment to the labor force. 
The KLIPS contains responses on life satisfaction for all years, on a five-point scale: Very satisfied; satisfied; middle; not satisfied; very unsatisfied. ${ }^{16}$ It also elicited responses about satisfaction with work hours and satisfaction with earnings (both on the same five-point scale). While we treat the dependent variable as continuous and present only least-squares estimates, we again also estimated every equation by ordered probit, with results that are qualitatively the same as those presented.

For all workers information on overtime hours was collected for each year. We used these responses to form three variables: An indicator for any overtime in the base year, and indicators for overtime hours between one and four per week (to match the specifics of the legislation) and five plus hours per week. The KLIPS also obtained all the usual demographic information, which we use to form indicators of marital status and educational attainment. The estimates also include a quadratic in age, so that we are using the same controls as in the previous section. We restrict the sample to individuals who worked in the base year and were age 22-49 in 1999 (32-59 in 2009), thus ensuring that nearly all those included would have completed schooling by the base year and would not have been of retirement age in the final year.

Descriptive statistics for the KLIPS samples are presented in Table 6. Life, hours and earnings satisfaction are shown for 1999 and 2009. The size of the sub-sample is far below half of the entire KLIPS sample. One reason for this is that overtime data are only collected for those who actually worked, which reduces the KLIPS sample down to around 3500. The remaining reductions are due to our restricting the age range in the sub-samples that we use and to the disqualification of the few workers who did not respond on the satisfaction questions in both years.

The average individual who worked in the base year (all members of the sub-samples) saw increased life satisfaction and satisfaction with these crucial aspects of work over this period. That ninety percent of the sub-sample are men results from its restriction to those who worked in both the Pre and Post periods. The average age is slightly below the mid-point of the eligible age range, consistent with

\footnotetext{
${ }^{16}$ We thank John Haisken-De New and Markus Hahn for instruction in the use of Panel Whiz (Hahn and HaiskenDeNew, 2013).
} 
labor-force participation declining in the late fifties in Korea. Most important for our purposes, forty percent of members of this sub-sample worked overtime in the Pre period, with over two-thirds of those working more than four hours of overtime per week.

A first look at differential changes in life satisfaction between workers whose hours in 1999 made them more or less likely to have been affected by the legislation can be obtained by examining the distribution of changes in life satisfaction, shown in Table 7. A quick perusal demonstrates that the distributions are almost identical. Indeed, the percentages of workers whose life satisfaction increased are 44 percent among those who worked no overtime in the Pre period, and 43 percent among those who did. Similarly, 14 percent of those without overtime in the Pre period had decreases in life satisfaction, 15 percent of those with overtime expressed lower life satisfaction. (The conclusion is the same if we use the complete 5x5 transition matrices.) The general inference from these data is that there is little difference in changes in life satisfaction between the two groups distinguished by the presence of overtime work in the base period.

Implicit in the statistics Table 7 are two assumptions: 1) The change in life satisfaction is independent of differences in workers' demographics, nor does it distinguish among those who worked overtime by the amount they worked; and 2) More important, it implicitly assumes that in an autoregression of current on ten-year lagged life satisfaction the parameter on the lagged satisfaction would be unity, which does not seem tenable. Accordingly, we estimate models relating current (2009) satisfaction to satisfaction in the base period (1999), a measure of base-period overtime work and the demographic variables discussed above. ${ }^{17}$

While the research design in this section differs entirely from that using the Korean GSS, the estimated impacts of the demographic variables on the life satisfaction measures are qualitatively identical. Thus holding base-period life satisfaction constant here, current life satisfaction is greater, other things equal, among the more educated and among married individuals. Indeed, where the

\footnotetext{
${ }^{17}$ Given the relatively small sample sizes, we pool men and women and include an indicator for gender. None of the results changes qualitatively if we exclude the small fraction of sample respondents who are women.
} 
demographic variables are measured comparably, the estimated impacts are even quantitatively very similar: Pooling men and women in the GSS, life satisfaction attains a minimum at age 43; in a comparably specified equation based on the KLIPS sub-sample, the minimum occurs at 45.

Because the legislation might have affected those who worked any overtime, not only those who worked just 1-4 overtime hours, we estimate all the models first using the indicator if the person worked any overtime in 1999, then using the separate indicators for 1-4 and 5+ hours of overtime. The upper panel in Table 8 includes the parameter estimates for base-period life satisfaction and the indicators for overtime work in 1999. The results in the first specification show that, all else equal, those who worked overtime in 1999 are significantly happier after the legislation has become fully effective, 0.13 standard deviations more than otherwise identical workers who put in no overtime in 1999. Moreover, if we use life satisfaction in 2010, which on average is two years after the legislation became fully effective, as the dependent variable, the estimate of the effect of the indicator for overtime in the base year 1999 is smaller and not significant statistically. The same is true if we use life satisfaction in 2007, during which entire year the legislation was still being phased in. ${ }^{18}$

The expanded specification that includes separate indicators for the amount of overtime worked, shown in the second column in the upper part of the table, indicates that most of the increase in life satisfaction occurred among those who worked substantial amounts of overtime. While we expect both those in the 41-44 and 45+ ranges of weekly hours to have been affected positively by the legislation, as the results show they were, it is somewhat surprising that the larger and more significant effect is on those who worked the most overtime in 1999. One possible explanation for this difference is that, as Table 6 shows, the number of people in this sub-sample who worked only 1-4 hours of overtime is fairly small.

The absence of GSS data for 1999 forced us to use 2003 as the Pre period in the previous section. Here we have both the 1999 data that we have used as the Pre-period and also 2003 data. We can thus examine how the results on these longitudinal data would differ if we had been forced to use 2003 as the

\footnotetext{
${ }^{18}$ There is substantial persistence in overtime: The one-year correlations between indicators of the presence of overtime in this sub-sample average +0.40 .
} 
Pre-period here by re-estimating the models in Table 8 using overtime status and life satisfaction in 2003 as the base. That re-estimation yields results in the same direction as those shown in the upper panel of Table 8, but with smaller impacts and less statistical significance. This comparison within the panel data set implies that the cross-section estimates in the previous section may be understating the impacts of the legislation on life satisfaction. The main point here, however, is that the results shown in Table 8, obtained by an entirely different method from those presented in Table 4, corroborate the latter completely, demonstrating again that the legislation appears to have improved the well-being of the workers at whom it was targeted.

The bottom panel of Table 8 lists the estimates of equations describing current satisfaction with hours (earnings) holding base-period satisfaction with hours (earnings) constant. The results on hours tend to confirm those of Estevão and Sá (2008), albeit on longitudinal data and on individuals, showing that workers affected by the legislation were increasingly happy with their hours, nearly significantly so for those who had worked 1-4 hours of overtime and quite significantly for those who had worked 5+ hours of overtime. While they were more satisfied with their earnings, with an impact in standard deviation units of 0.11 , the difference in satisfaction with earnings in 2009 by overtime status in 1999 is not quite statistically significant. Even the weak positive effect is somewhat surprising, since we know that total earnings did not rise among workers affected by the legislation. Thus the affected workers either are thinking about earnings per hour when responding about their satisfaction with earnings, or they cannot separate various aspects of their job when asked separate questions about them.

\section{Joint Estimation of a Household Model}

Throughout the analysis we have treated individuals' satisfaction as determined solely by their demographic characteristics and the possible direct impact of the legislation on them. In a married couple, however, changes in one spouse's hours of work induced by the legislation may: 1) Alter the other spouse’s hours of work (Stancanelli and van Soest, 2012; Goux et al, 2014) and also change his/her allocation of non-market time. These changes may in turn lead to a change in the spouse's life satisfaction; and 2) Even with no change in the spouse's time allocation, his/her satisfaction may be 
altered by the induced direct effect on the time allocation and/or life satisfaction of the spouse who was directly affected by the legislation. These two mechanisms suggest examining the interactions of spouses' satisfaction in response to the labor-market shocks that each faced during the period when legislation that reduced the demand for weekly hours was enacted.

While the Japanese data set included only one respondent per household, the Korean GSS includes all adults. ${ }^{19}$ Taking married men ages $19-64$ and women ages 16-64, we use the Korean GSS to form couples, which are the unit of observation in this Section. ${ }^{20}$ For each couple in the Pre- and Postyears (2003 and 2009) we include all the controls used in Section IV and assign the imputed propensity scores $\pi^{\mathrm{h}}$ and $\pi^{\mathrm{w}}$ as the husband's and wife's propensities to have been affected by the legislation.

Before examining the impacts of the spouses' likelihoods of being affected by the legislated incentives to employers to reduce weekly hours, we first examine the relationship between the spouses’ life satisfaction in the two cross sections. The contingency table relating the husband's and wife's life satisfaction is presented in Table 9 for the 27,150 couples in the sample. In over half the couples the partners' expressions of life satisfaction are identical, and in over ninety percent the spouses' subjective well-being is no more than one point apart. ${ }^{21}$ (The chi-square test of randomness in this contingency table is $\chi^{2}(16)>13,000, p<0.001$.) These results mirror those in research that has focused on the joint life satisfaction of spouses (Guven et al, 2012) and suggest that using this sample of couples to study people's reactions to their spouse's labor-market shocks rests on a firm basis.

As a first step we estimate (2b) as in Table 4, except that we add as controls in the estimates for the husband (wife) his (her) spouse's demographics (age and education), and the terms $\pi^{\mathrm{w}}\left(\pi^{\mathrm{h}}\right)$ both individually and interacted with the indicator D2009 for the Post period. The estimates are shown in

\footnotetext{
${ }^{19}$ This exercise is also possible using the KLIPS, but the small sample size makes analyzing couples' behavior in this area of little value.

${ }^{20}$ There are a number of multiple-adult households in these data. To be sure that we match husband and wife, we use only one couple per household, match by searching on the adults' ages, requiring that the husband be no more than 15 years older than his wife, that the wife be no more than 10 years older than her husband, and using the older(st) couple if there are two or more matched couples.

${ }^{21}$ We were told that each spouse answers sensitive questions like this outside the presence of the other spouse. The similar responses thus do not arise from one partner answering the question for the other.
} 
Columns (1) and (2) of Table 10 for the husband and wife respectively. Examining the estimates of the impact of one's own probability of having been affected after the legislation ( $\pi^{\mathrm{h}} \cdot \mathrm{D} 2009$ in Column (1)) in this sample compared to the estimates for all men in Column (1) of Table 4, there are no major changes. For women also the estimate of the impact of the legislation, the coefficient on $\pi^{\mathrm{w}} \cdot \mathrm{D} 2009$ in Column (2), is tiny and statistically insignificant. Similarly, the cross-effects (of one spouse's propensity to have been affected by the legislation on the other spouse's life satisfaction) are small and statistically insignificant in this model that includes all the controls and their interaction with D2009.

The two-equation model that we have estimated is ad hoc. To be a bit formal, let us first assume for convenience of notation that we can equate life satisfaction with utility $U$. Then we can write the spouses’ utility as:

(3a) $U^{h}=\alpha_{1} U^{w}\left(\pi^{h}, \pi^{w}\right)+\alpha_{2} \pi^{h}$,

and:

(3b) $U^{w}=\beta_{1} U^{h}\left(\pi^{h}, \pi^{w}\right)+\beta_{2} \pi^{w}$ ，

which allows us to test various hypotheses about the jointness of their life satisfaction and the effects of each spouse's likelihood of being affected by the legislation on theirs and their spouse's satisfaction. ${ }^{22}$ Differentiating (3a) and (3b), these four effects, two own- and two cross-effects, can be written as:
(4a) $\frac{\partial U^{h}}{\partial \pi^{h}}=\alpha_{1} \frac{\partial U^{w}}{\partial \pi^{h}}+\alpha_{2}$;
(4b) $\frac{\partial U^{h}}{\partial \pi^{w}}=\alpha_{1} \frac{\partial U^{w}}{\partial \pi^{w}}$;
(4c) $\quad \frac{\partial U^{w}}{\partial \pi^{h}}=\beta_{1} \frac{\partial U^{h}}{\partial \pi^{h}}$;
(4d) $\quad \frac{\partial U^{w}}{\partial \pi^{w}}=\beta_{1} \frac{\partial U^{h}}{\partial \pi^{w}}+\beta_{2}$.

\footnotetext{
${ }^{22}$ One of the earliest efforts to specify and estimate a joint household utility function was Browning et al (1994).
} 
Based on this joint model we estimate the system:

$$
\begin{aligned}
& \mathrm{S}^{\mathrm{h}}=\alpha_{1} S^{w}+\alpha_{2} \pi^{h} \cdot D 2009+a_{1} \pi^{h}+a_{2} D 2009+[1+D 2009] \cdot X \gamma^{h}+u_{h} \\
& \mathrm{~S}^{\mathrm{w}}=\beta_{1} S^{h}+\beta_{2} \pi^{w} \cdot D 2009+b_{1} \pi^{w}+b_{2} D 2009+[1+D 2009] \cdot X \gamma^{w}+u_{w},
\end{aligned}
$$

using GMM, where $S^{i}$ is the married person's life satisfaction, the parameters $a_{i}, b_{i}$ and $\gamma^{i}$ are essential for the model but do not enter the calculation of the impact of the change in the propensity scores on the life satisfaction of the partners, and $\mathrm{X}$ is a vector of controls (the age and education of both spouses). Note that, as in the estimates in the left-hand panel of Table 10, we include both the controls $\mathrm{X}$ and their interactions with the Post indicator, D2009. Equations (5) generate estimates of the partial derivatives (4) and allow us to infer whether there are cross-effects of one spouse's satisfaction on the other's. More important for our purpose, they indicate the magnitude of the direct and indirect effects on each spouse's life satisfaction of the likelihood of having been affected by the hours legislation.

Column (3) of Table 10 contains the estimates of the parameters in (5) in which the controls and their interactions with D2009 are excluded, while Column (4) presents the parameter estimates from a model that adds these terms. Looking first at the cross-effects of spouse's life satisfaction, the estimates of $\alpha_{1}$ and $\beta_{1}$, the spouses' life satisfaction is mutually dependent (both parameters are statistically significantly nonzero). Moreover, the husband's life satisfaction has a greater impact on his wife's life satisfaction than the obverse, significantly so in the estimates in Column (3).

Considering the estimates of the structural derivatives, the estimates of the equations without controls reproduce the results in Table 4-the implied effect of the legislation on Korean men is significantly positive, while for women there is no significant effect. When we include the controls and their interactions, all the direct impacts disappear, as in the estimates of (2b) in Table 4. The cross-effect of a wife's likelihood of being affected by the legislation on the husband's satisfaction is not significantly different from zero; but if we exclude the controls a husband with a greater likelihood of being affected sees his wife's life satisfaction increase significantly. In sum, we are again left with an inability to distinguish the impact of the legislation from simultaneous changes in relative life satisfaction that may be correlated with the same demographics that determine the likelihood of being affected by the law. We 
have, however, demonstrated that the differential increase in men's likelihood of having been affected by the legislation is correlated with and perhaps causes an increase in their wives' relative life satisfaction.

By what mechanism might the husband's propensity to have had his hours reduced by the legislation generate the indirect effect on his wife's happiness that is consistent with the results in Column (3) of Table 10? Using time-diary data we showed (Kawaguchi et al, 2013) that there was very little evidence that the wife's time allocation changed in response to a change in $\pi^{\mathrm{h}}$. Nor was there any evidence that husbands who were likely to have been affected by the legislation allocated more time to household production. Those being the case, the indirect effect on the wife's satisfaction must instead work through her greater satisfaction from having her husband enjoying more leisure, either because, as suggested by the results in Hamermesh (2002), the pleasure that she derives from their joint and synchronized consumption of leisure exceeds that of her husband, or because purely altruistically she values his extra leisure.

\section{Conclusions and Implications}

Using legislated changes in the length of the standard workweek in Japan and Korea as exogenous shocks, we have examined how workers' life satisfaction changed in response to the shorter workweeks that employers imposed upon workers because the high price of an hour of overtime became effective with fewer hours worked. Our estimates on pooled cross-section data generally suggest that this legislation, whose purpose was to reduce what had been viewed as long hours in both countries (and which did stand out in international comparisons), probably made targeted workers better off. Indeed, among women in Japan and men in Korea we find that those workers who were more likely to have been affected by the legislation were significantly better off relative to otherwise similar workers. These results are confirmed using longitudinal data from Korea. Moreover, estimates of a household model suggest that Korean married men's reduced hours of market work increased the well-being of their wives too.

The difficulty with these inferences is that the same factors that affected the likelihood of the legislation having reduced particular workers' hours are also correlated with differential increases in satisfaction among those same workers. Examinations of temporally adjacent data suggest, however, that 
there were no longer-term trends in these relative effects in either country. Nor were there any general trends in both countries - in tax progressivity or returns to schooling and experience- that can explain the findings; and we do not observe the same results for self-employed workers, who could not have been affected by the legislation. Either the legislation had positive impacts on particular workers' well-being, or something else occurred in each country that differentially benefited particular groups of workers and did so only during the period when the laws were being implemented.

This examination implies, at least in these two countries at these particular times, that the labor market may have previously been in an equilibrium that left workers worse off than if they had worked fewer hours. Some mechanism created a situation in which workers would have preferred a wage-hours package that included fewer hours. Altering the price that employers must pay for an extra hour of labor created the incentives for them to offer that package, incentives that might not have been generated without this regulation of the unregulated labor market.

While we noted that there are several reasons why the legislation may have improved outcomes for those directly affected, one of those is that workers are in a "rat race," perhaps stemming from desires to demonstrate their quality to employers, perhaps from other bases for interdependence. While the ratrace is hardly new, we do not believe it has been tested directly before, and certainly not in the context of protective legislation. Thus one interpretation of our results is as a demonstration that the rat-race model may have some general validity.

We should stress that we have only presented two examples. Our results do not even imply that these regulations improved overall economic welfare in these two economies - the gains that we have demonstrated were reaped by certain workers might have been offset by losses imposed on others in the population. All we have shown is that those workers who were more likely to have been affected by the legislation — those at whom it was aimed—saw their satisfaction increase relative to that of others and were thus presumptively made better off.

Our results say nothing about whether similar regulations in other labor markets would have the same positive impacts on workers. If hours of work had been lower in these two economies then, as they 
are now and as they were then in most Western economies, the same effects might well not have been observed. All we have shown is that there are cases in developed economies in which workers' wellbeing may be improved by interventions in the labor market that provide incentives to reduce hours of work.

\section{REFERENCES}

Ran Abramitzky, Adeline Delavande and Luis Vasconcelos, "Marrying Up: The Role of Sex Ratio in Assortative Matching,” American Economic Journal: Applied Economics, 3 (July 2011): 124-57.

Mark Aguiar and Erik Hurst, and Loukas Karabarbounis, “Time Use During the Great Recession,” American Economic Review, 103 (Aug. 2013): 1664-96.

George Akerlof, "The Economics of Caste and of the Rat Race and Other Woeful Tales," Quarterly Journal of Economics, 90 (Nov. 1976): 599-617.

David Blanchflower and Andrew Oswald, "Well-Being over Time in Britain and the USA," Journal of Public Economics, 88 (July 2004): 1359-86.

Irene Botasaru and Federico Gutierrez, "Difference-in-Differences When Treatment Status is Observed in Only One Period,” Unpublished paper, Vanderbilt University, 2014

Martin Browning, François Bourguignon, Pierre-André Chiappori and Valerie Lechene, "Income and Outcomes: A Structural Model of Intrahousehold Allocation,” Journal of Political Economy, 102 (Dec. 1994): 1067-96.

Michael Burda and Daniel Hamermesh, "Unemployment, Market Work and Household Production," Economics Letters, 107 (May 2010): 131-3.

Andrew Clark, Ed Diener, Yannis Georgellis and Richard Lucas, "Lags and Leads in Life Satisfaction: A Test of the Baseline Hypothesis,” Economic Journal, 118 (June 2008): F222-43.

Susan Dynarski, "The Behavioral and Distributional Implications of Aid for College," American Economic Association, Papers and Proceedings, 92 (May 2002): 279-85.

Ronald Ehrenberg, Fringe Benefits and Overtime Behavior: Theory and Econometric Analysis. Lexington, MA: Heath, 1971.

Marcello Estevão and Filippa Sá, “The 35-Hour Workweek: Straightjacket or Welfare Improvement?” Economic Policy, 55 (July 2008): 418-63.

Paul Frijters, John Haisken-DeNew and Michael Shields, “'Money Does Matter: Evidence from Increasing Real Income and Life Satisfaction in East Germany Following Reunification,” American Economic Review, 94 (June 2004): 730-40.

Dominique Goux, Eric Maurin and Barbara Petrongolo, "Worktime Regulations and Spousal Labor Supply,” American Economic Review, 104 (Jan. 2014): 252-76. 
Jon Gruber and Sendhil Mullainathan, “Do Cigarette Taxes Make Smokers Happier?” B.E. Journal of Economic Analysis and Policy, Advances 5(1), (2005): 1-45.

Cahit Guven, Claudia Senik and Holger Stichnoth, "You Can’t Be Happier Than Your Wife: Happiness Gaps and Divorce,” Journal of Economic Behavior and Organization, 82 (April 2012): 110-30.

Markus Hahn and John Haisken-DeNew, "Panel Whiz and the Australian Longitudinal Data Infrastructure in Economics,” Australian Economic Review, 46 (2013): 1-8.

Daniel Hamermesh, Labor Demand. Princeton, NJ: Princeton University Press, 1993.

(Nov. 2002): 601-23.

Daniel Hamermesh and Jason Abrevaya, “'Beauty Is the Promise of Happiness'?” European Economic Review, 64 (Nov. 2013): 351-68.

Daniel Hamermesh and Joel Slemrod, “The Economics of Workaholism: We Should Not Have Worked on This Paper,” B.E. Journal of Economic Analysis and Policy, Contributions, 8(1), (2008):1-30.

Robert Hart, The Economics of Overtime Working. Cambridge: Cambridge University Press, 2004.

Fumio Hayashi and Edward Prescott, "The 1990s in Japan: A Lost Decade," Review of Economic Dynamics, 5 (Jan. 2002): 206-35.

Ryo Kambayashi, Daiji Kawaguchi and Izumi Yokoyama, "Wage Distribution in Japan, 1989-2003," Canadian Journal of Economics, (Nov. 2008): 1329-50.

Daiji Kawaguchi, Jungmin Lee and Daniel Hamermesh, “A Gift of Time,” Labour Economics, 24 (Oct. 2013): 205-16.

Renée Landers, James Rebitzer and Lowell Taylor, "Rat Race Redux: Selection in the Determination of Work Hours in Law Firms,” American Economic Review, 86 (June 1996): 329-49.

Richard Layard, “Happiness and Public Policy: The Challenge to the Profession,” Economic Journal, 116 (March 2006): C24-C33.

Jungmin Lee, Daiji Kawaguchi and Daniel Hamermesh, “Aggregate Impacts of a Gift of Time," American Economic Association, Papers and Proceedings, 102 (May 2012): 612-16.

Paul Levine, Peter McAdam and Peter Welz, “On Habit and the Socially Efficient Level of Consumption and Work Effort,” School of Economics Discussion Papers 0713, University of Surrey, 2013.

Jens Ludwig, Greg Duncan, Lisa Gennetian, Lawrence Katz, Ronald Kessler, Jeffrey Kling and Lisa Sanbonmatsu, 2012. "Neighborhood Effects on the Long-Term Well-Being of Low-Income Adults,” Science, 337(6101): 1505-10.

Alan Manning. Monopsony in Motion: Imperfect Competition in Labor Markets. Princeton, NJ: Princeton University Press, 2003.

Charles Manski, “Identification of Endogenous Social Effects: The Reflection Problem,” Review of Economic Studies, 60 (July 1993): 531-42. 
Donna G. Matias, Women and Entrepreneurship in California: Obstacles, Incentives and Reform. Pacific Research Institute, San Francisco, 2002.

Katsuo Nishiyama and Jeffrey Johnson, 1997. "Karoshi-Death from Overwork: Occupational Health Consequences of Japanese Production Management,” International Journal of Health Services, 27(4): 625-641.

Silvia Pezzini, “The Effect of Women's Rights on Women's Welfare: Evidence from a Natural Experiment,” Economic Journal, 115 (March 2009): C208-27.

Sherwin Rosen, "Hedonic Prices and Implicit Markets: Product Differentiation in Pure Competition," Journal of Political Economy, 82 (Jan.-Feb. 1974): 34-55.

Elena Stancanelli and Arthur van Soest, "Joint Leisure Before and After Retirement: A Double Regression Discontinuity Approach,” IZA Discussion Paper No. 6698, 2012.

Betsey Stevenson and Justin Wolfers, "The Paradox of Declining Female Happiness," American Economic Journal: Economic Policy, 1 (Aug. 2009): 190-225.

Stephen Trejo, “The Effects of Overtime Pay Regulation on Worker Compensation,” American Economic Review, 81 (Sept. 1991): 719-40. 
Table 1. Logit Estimates of the Propensity to Be Affected by the Cut in Standard Hours, Based on Time Diary Surveys

\begin{tabular}{|c|c|c|c|c|c|}
\hline \multicolumn{4}{|c|}{ JAPAN } & \multicolumn{2}{|c|}{ KOREA } \\
\hline & MEN & WOMEN & & MEN & WOMEN \\
\hline High school & $\begin{array}{l}0.335 \\
(0.014)\end{array}$ & $\begin{array}{l}-0.067 \\
(0.017)\end{array}$ & Education (years) & $\begin{array}{c}0.635 \\
(0.102)\end{array}$ & $\begin{array}{c}0.178 \\
(0.098)\end{array}$ \\
\hline Junior college & $\begin{array}{l}0.363 \\
(0.024)\end{array}$ & $\begin{array}{c}0.173 \\
(0.021)\end{array}$ & Education (years) $^{2}$ & $\begin{array}{l}-0.005 \\
(0.003)\end{array}$ & $\begin{array}{c}0.008 \\
(0.002)\end{array}$ \\
\hline University & $\begin{array}{l}0.464 \\
(0.017)\end{array}$ & $\begin{array}{c}0.163 \\
(0.030)\end{array}$ & Student & $\begin{array}{c}-0.751 * \\
(0.139)\end{array}$ & $\begin{array}{l}-0.792 \\
(0.179)\end{array}$ \\
\hline Age & $\begin{array}{l}0.193 \\
(0.002)\end{array}$ & $\begin{array}{c}0.133 \\
(0.003)\end{array}$ & Age & $\begin{array}{c}0.374 \\
(0.024)\end{array}$ & $\begin{array}{c}0.165 \\
(0.034)\end{array}$ \\
\hline $\mathrm{Age}^{2} / 100$ & $\begin{array}{l}-0.222 \\
(0.003)\end{array}$ & $\begin{array}{l}-0.194 \\
(0.003)\end{array}$ & Age $^{2} / 100$ & $\begin{array}{l}-0.356 \\
(0.019)\end{array}$ & $\begin{array}{l}-0.177 \\
(0.028)\end{array}$ \\
\hline & & & Age $*$ years of schooling & $\begin{array}{l}-0.006 \\
(0.001)\end{array}$ & $\begin{array}{l}-0.005 \\
(0.001)\end{array}$ \\
\hline & & & Metro area & $\begin{array}{l}-0.310 \\
(0.046)\end{array}$ & $\begin{array}{l}-0.193 \\
(0.064)\end{array}$ \\
\hline $\begin{array}{l}\text { Mean of dependent } \\
\text { variable } \\
\text { Mean of predicted } \\
\text { values }\end{array}$ & $\begin{array}{l}0.184 \\
0.184\end{array}$ & $\begin{array}{l}0.118 \\
0.118\end{array}$ & $\begin{array}{l}\text { Mean of dependent } \\
\text { variable } \\
\text { Mean of predicted } \\
\text { values }\end{array}$ & $\begin{array}{l}0.099 \\
0.095\end{array}$ & $\begin{array}{l}0.038 \\
0.039\end{array}$ \\
\hline $\mathrm{N}$ & 224,665 & 248,250 & $\mathrm{~N}$ & 36,457 & 41,959 \\
\hline
\end{tabular}


Table 2. Descriptive Statistics, National Surveys Japan, 1984, 1987 (Pre), 1996, 1999 (Post), Ages 15-64; GSS Korea, 2003 (Pre), 2009 (Post), Ages 16-64 (Mean, Standard Deviation, Range)*

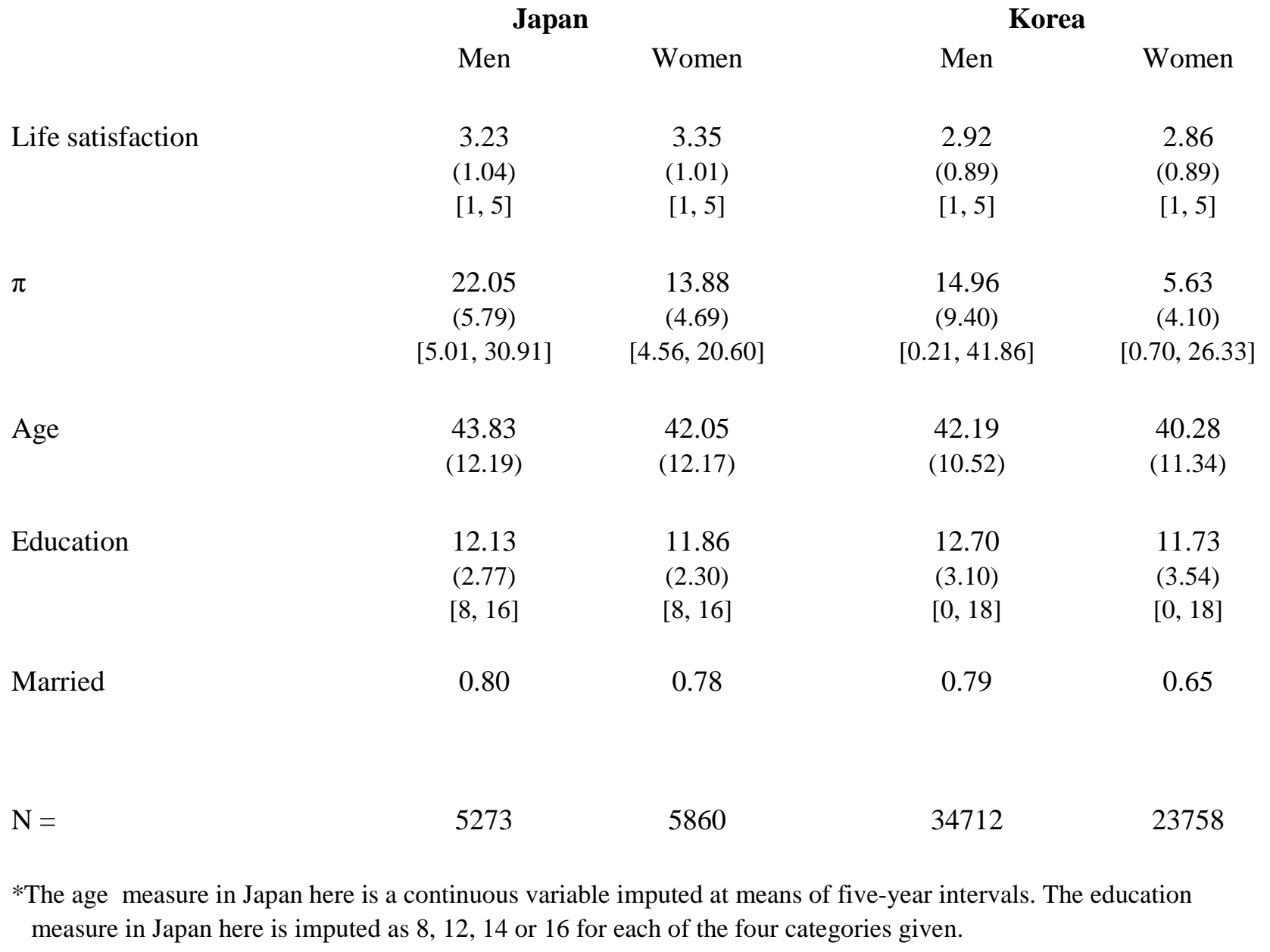


Table 3. Determinants of Life Satisfaction, Japan, 1984, 1987, 1996 and 1999, Ages 15-64*

Men (N=5273)

Equation:

(2a)
$-0.0049$

(0.0095)

D96-99

$\pi \cdot \mathrm{D} 96-99$

$-0.3708$

$(0.1482)$

0.0063

(0.0069)

$\mathrm{X}$ and interactions:

Adj. $\mathrm{R}^{2}$

No

0.013
(2b)

$$
-0.0242
$$

$-2.6479$

(0.8525)

0.1286

(0.0446)

Yes

0.065
Women ( $\mathrm{N}=5860)$

$$
\text { (2a) }
$$

$-0.0271$

$-0.1089$

(0.0060)

(0.0532)

$-0.5193$

$-1.7074$

(0.1036)

(0.6531)

0.0174
$(0.0068)$

0.2156

(0.0854)

No Yes

0.025

0.059

*The regressions in Columns (2) and (4) also include an indicator of marital status, and vectors of indicators of five-year age ranges and of educational attainment and interactions of these with D96-99. The standard errors are clustered on the propensity-score cells. 
Table 4. Determinants of Life Satisfaction, Korea, 2003 and 2009, Ages 16-64*

Men (N=34712)

Equation:

Ind. Var.:

$\pi$

D2009

$\pi \cdot \mathrm{D} 2009$

$-0.0915$

$(0.0212)$

$(0.0012)$

$-0.5511$

$(0.2249)$

$-0.0046$

(0.0026)

0.0024

$(0.0031)$

0.0442

0.0259

(0.0029)

$(0.0038)$

0.0060

$-0.2018$

$(0.0224)$

(0.1924)

0.0036

$(0.0051)$

$\mathrm{X}$ and

interactions:

No

Yes

No

Yes

Adj. $\mathrm{R}^{2}$

0.059

0.044

0.061

*The regressions in Columns (2) and (4) also include an indicator of marital status, years of educations, a quadratic in age, and interactions of these with D2009. The standard errors are clustered on the propensity-score cells. 
Table 5. Placebo Tests for Trends in Life Satisfaction, Japan, 1996, 1999, and 2002, 2005, Ages 15-64; Korea, 1990 and 2001, Ages 16-64

\begin{tabular}{lcccc}
\multicolumn{2}{c}{ Japan } & & \multicolumn{2}{c}{ Korea } \\
& Men & Women & Men & Women \\
Ind. Var.: & & & \\
$\pi$ & 0.0014 & -0.0097 & 0.0975 & 0.0253 \\
& $(0.0071)$ & $(0.0059)$ & $(0.0159)$ & $(0.0272)$ \\
& & & & -0.1913 \\
$(\mathrm{D} 2002,2005$ Japan $)$ & -0.2627 & -0.1626 & -0.0311 & $(0.2550)$ \\
$(\mathrm{D} 2001$ Korea) & $(0.1672)$ & $(0.0736)$ & $(0.2733)$ & -0.0401 \\
$\pi \cdot \mathrm{D} 2002,2005$ & & & & $(0.0355)$ \\
$\pi \cdot \mathrm{D} 2001$ & 0.0069 & 0.0023 & -0.0689 & \\
& $(0.0067)$ & $(0.0051)$ & $(0.0201)$ & 0.007 \\
Adj. $\mathrm{R}^{2}$ & & & & 0.053 \\
\end{tabular}


Table 6. Descriptive Statistics, KLIPS, Workers in Base Year, Ages 32-59 in 2009 N=1023 (Mean, Standard Deviation)

$\begin{array}{lccc}\text { Life satisfaction } 1999 & 3.16 & \text { Satisfaction with hours 1999 } & 3.10 \\ & (0.80) & & (0.86) \\ \text { Life satisfaction } 2009 & & & \\ & 3.52 & \text { Satisfaction with hours 2009 } & 3.35 \\ & (0.59) & & (0.77) \\ \text { Age 2009 } & 45.02 & \text { Satisfaction with earnings 1999 } & 2.61 \\ & (7.05) & & (0.83) \\ \text { Male } & & & \\ & 0.900 & \text { Satisfaction with earnings } 2009 & 2.97 \\ & & & (0.79)\end{array}$

1-4 hours overtime $1999 \quad 0.128$

5 plus hours overtime

$1999 \quad 0.277$

Overtime hours $1999 \quad 3.502$

(unconditional) $\quad(6.14)$ 
Table 7. Change in Life Satisfaction, Korea 1999 to 2009, KLIPS, People Age 32-59, 2009, N = 1023 (percent distributions)

Overtime in 1999

\section{Change in}

Life Satisfaction

$\begin{array}{ccc} & \text { No } & \text { Yes } \\ \mathbf{- 2} & 1.77 & 0.48 \\ \mathbf{- 1} & 12.67 & 14.78 \\ \mathbf{0} & 41.30 & 41.63 \\ \mathbf{1} & 34.90 & 36.54 \\ \mathbf{2} & 8.67 & 6.13 \\ \mathbf{3} & 0.69 & 0.44\end{array}$


Table 8. Impact of 1999 Overtime Hours on Satisfaction with Life and Job Aspects in 2009, KLIPS $\mathrm{N}=1023 *$

\section{Life Satisfaction}

$\begin{array}{llc}\text { Satisfaction } & 0.131 & 0.116 \\ 1999 & (0.022) & (0.022) \\ & & \\ \text { Any overtime 1999 } & \begin{array}{l}0.079 \\ (0.035)\end{array} & ------ \\ & & \\ \text { Overtime 1-4 hours } & ------- & 0.024 \\ & & (0.053) \\ \text { Overtime 5+ hours } & ------- & 0.105 \\ & & 0.040) \\ \text { Adj. } \mathrm{R}^{2} & 0.137 & 0.136\end{array}$

\section{Hours Satisfaction Earnings Satisfaction}

\begin{tabular}{|c|c|c|c|c|}
\hline Satisfaction 1999 & $\begin{array}{c}0.116 \\
(0.027)\end{array}$ & $\begin{array}{c}0.119 \\
(0.027)\end{array}$ & $\begin{array}{c}0.084 \\
(0.030)\end{array}$ & $\begin{array}{c}0.083 \\
(0.030)\end{array}$ \\
\hline Any overtime 1999 & $\begin{array}{c}0.198 \\
(0.048)\end{array}$ & ------- & $\begin{array}{c}0.083 \\
(0.050)\end{array}$ & ------- \\
\hline Overtime 1-4 hours & ------- & $\begin{array}{c}0.126 \\
(0.072)\end{array}$ & -------- & $\begin{array}{r}0.036 \\
(0.075)\end{array}$ \\
\hline Overtime 5+ hours & ------- & $\begin{array}{c}0.232 \\
(0.054)\end{array}$ & -------- & $\begin{array}{l}0.105 \\
(0.056)\end{array}$ \\
\hline Adj. $\mathrm{R}^{2}$ & 0.092 & 0.093 & 0.061 & 0.061 \\
\hline
\end{tabular}


Table 9. Distribution of Couples' Life Satisfaction, Korea, 2003 and 2009, $\mathrm{N}=\mathbf{2 7 , 1 5 0}$

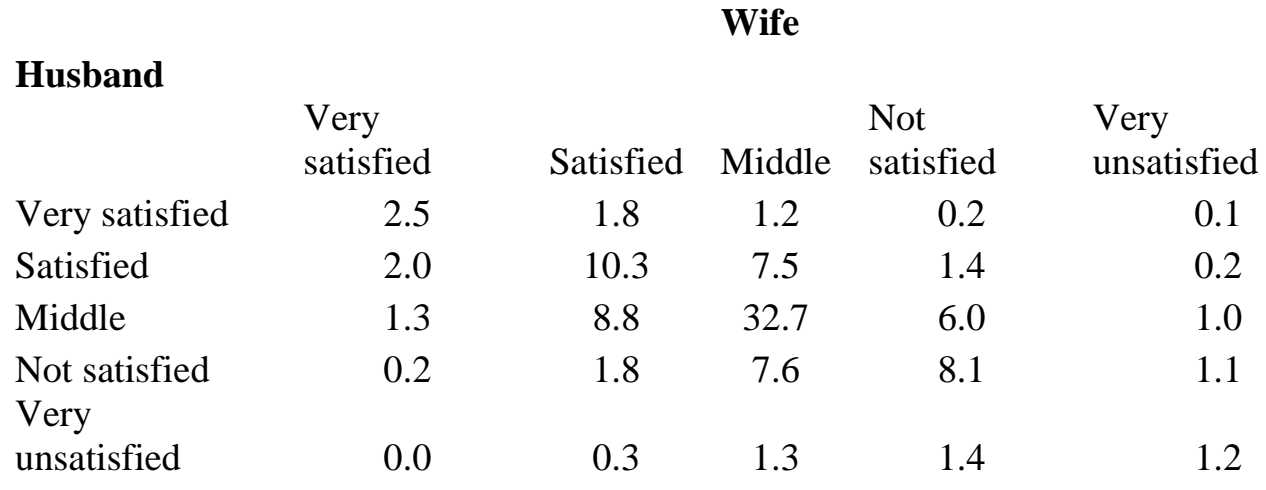


Table 10. Joint Models of Spouses' Life Satisfaction, Korea, 2003 and 2009, N=27,150*

\section{Husband Wife}

Ind. Var.

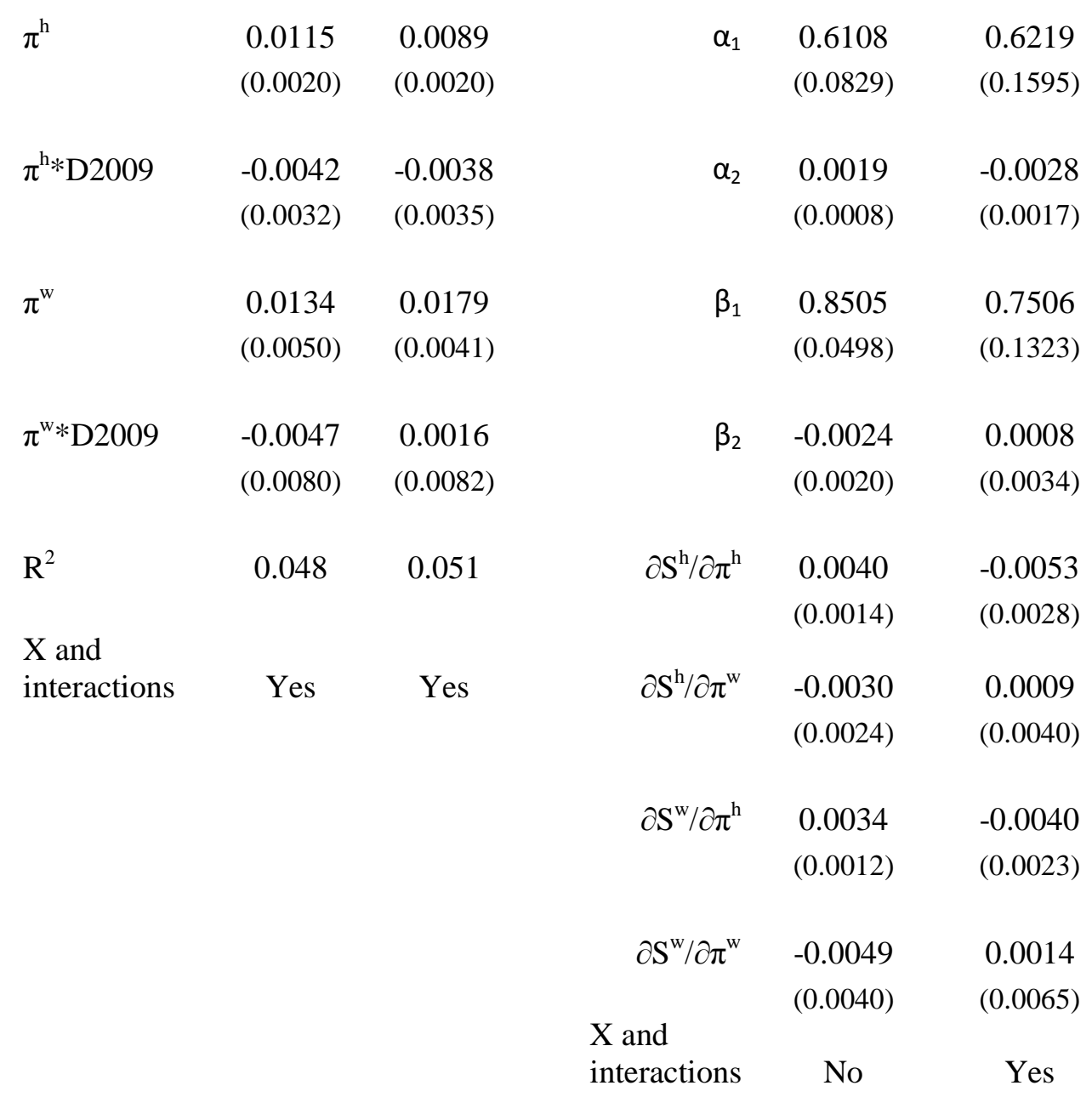

*Each equation also includes continuous variables measuring each spouse's education and quadratics in each spouse's age, and the interactions of these variables with D2009. 


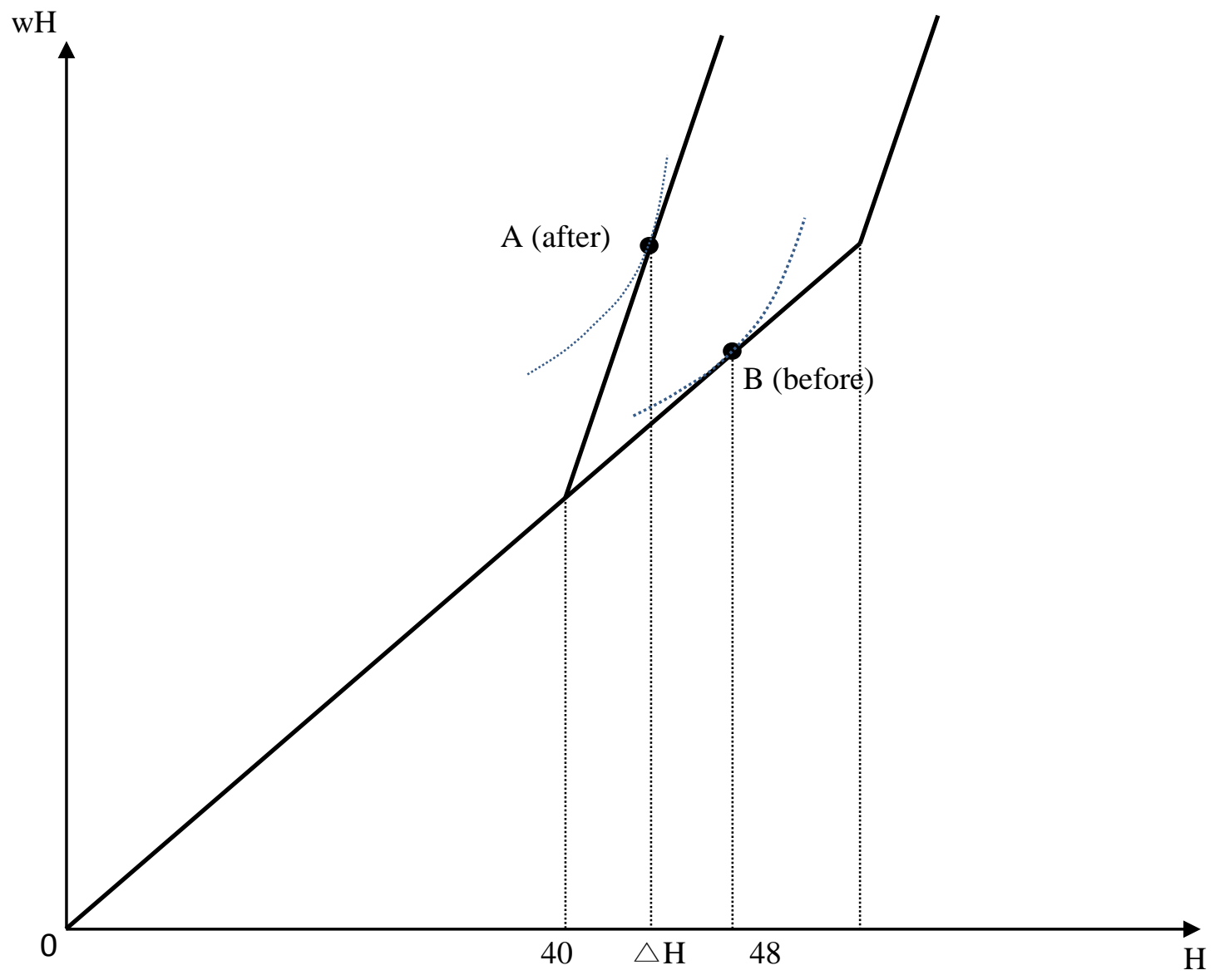

Figure 1a. Worker Well-Being with a Decrease in Standard Hours and No Change in Straight-time Wage rates 


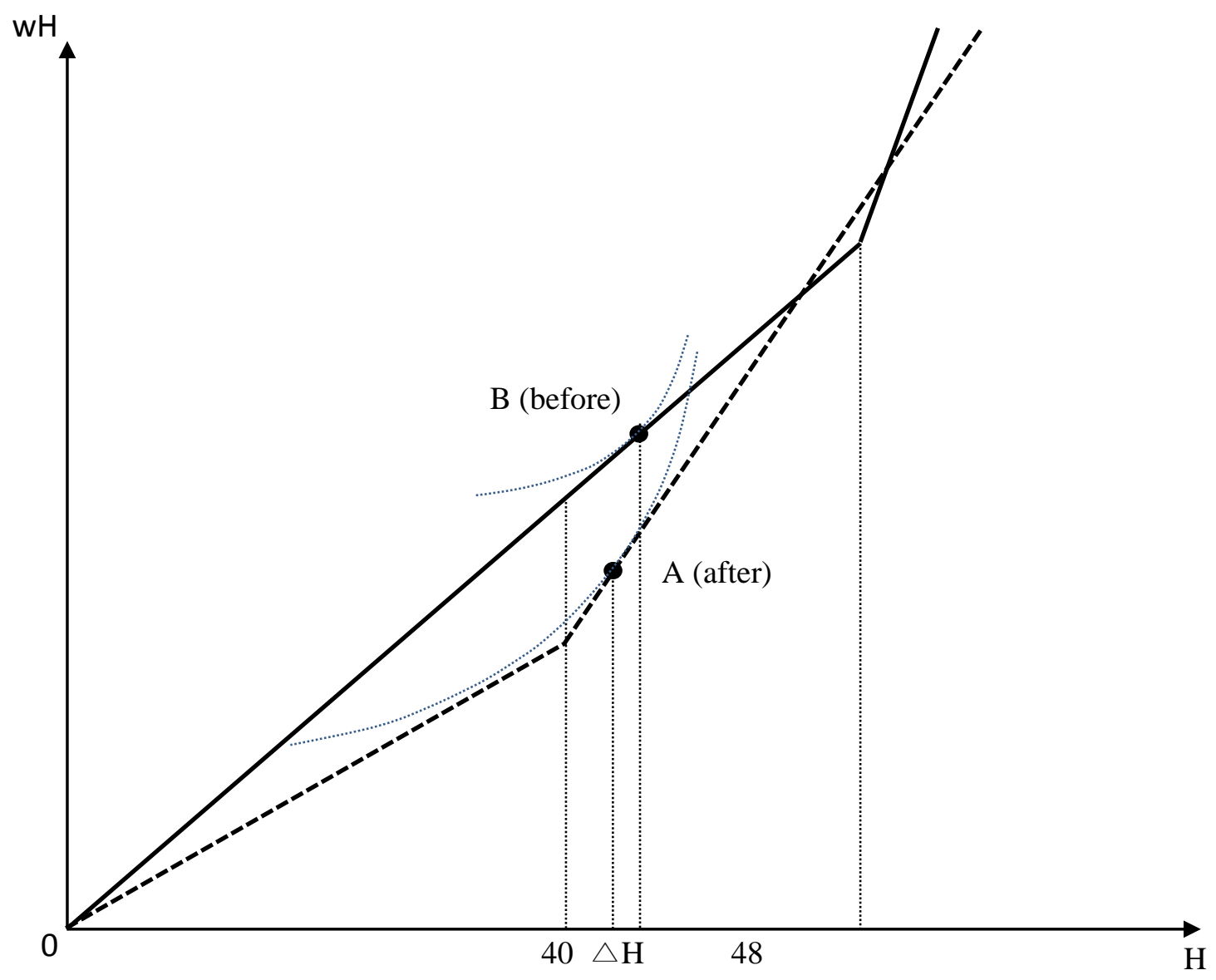

Figure 1b. Worker Well-Being with a Decrease in Standard Hours and a Drop in Straighttime Wage Rates 


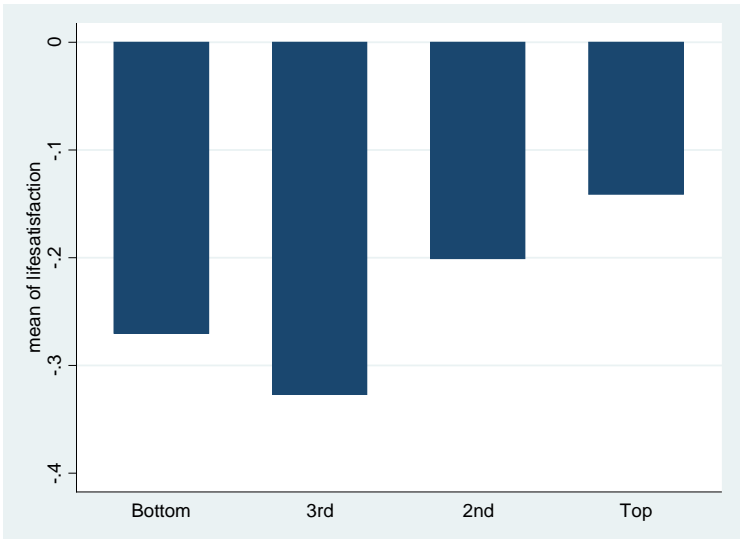

Figure 2a. Life Satisfaction Post-Pre, Japan, By $\pi$ Quartile, Males

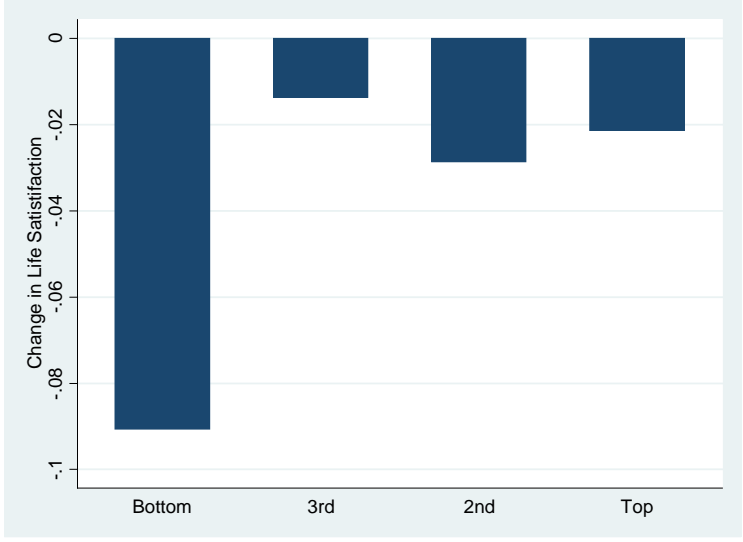

Figure 3a. Life Satisfaction Post-Pre, Korea, By $\pi$ Quartile, Males

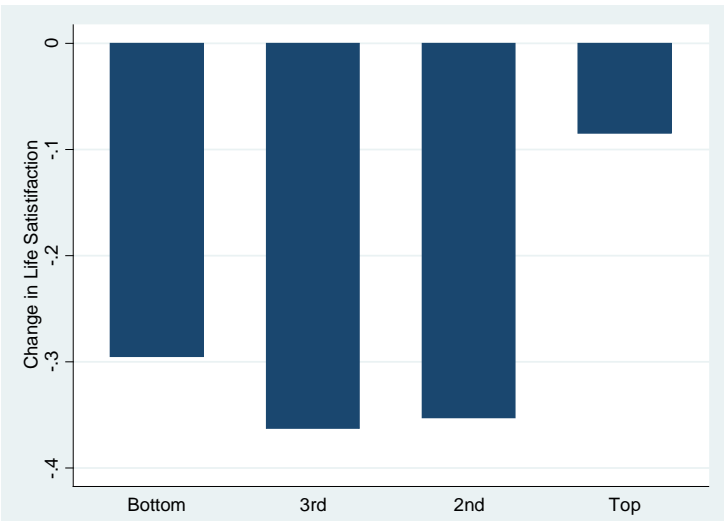

Figure 2b. Life Satisfaction Post-Pre, Japan, By $\pi$ Quartile, Females

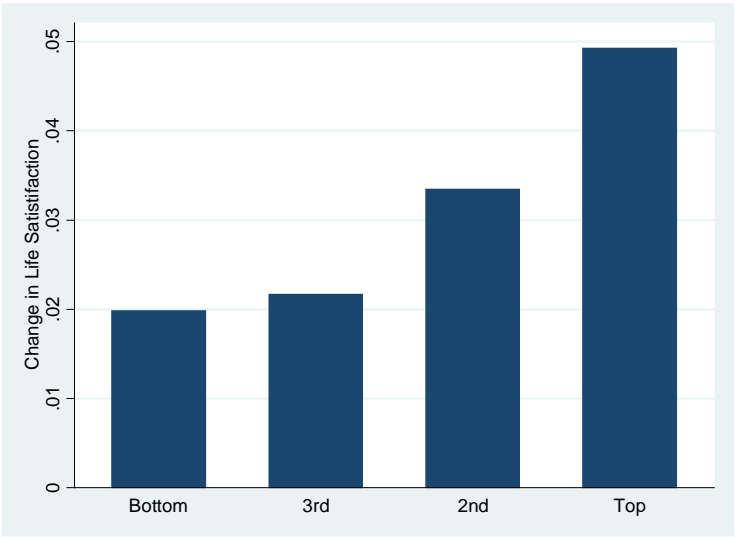

Figure 3b. Life Satisfaction Post-Pre, Korea, By $\pi$ Quartile, Females 